Robert, L. P. (forthcoming), Healthy Divide or Detrimental Division? Subgroups in Virtual Teams, Journal of Computer Information Systems

\title{
Healthy Divide or Detrimental Division? Subgroups in Virtual Teams
}

\author{
Lionel P. Robert Jr.* \\ School of Information \\ University of Michigan \\ Ann Arbor, MI, USA \\ Phone: $734-764-5296$ \\ Fax: 734-615-3587 \\ Iprobert@umich.edu
}




\title{
Healthy Divide or Detrimental Division? Subgroups in Virtual Teams
}

\author{
Lionel P. Robert Jr.*
}

\begin{abstract}
Subgroup formation, the emergence of smaller groups within teams, has been found to be detrimental to teamwork in virtual teams. Recently, however, an alternative view of the effects of subgroup formation proposes that the formation of subgroups is not always bad. When subgroups are based on identity characteristics like race and gender they are likely to have negative effects, but when they are not, subgroups can have positive effects on teamwork. This paper empirically examines this proposition. Results of our study generally support the proposed assertion. When subgroups are not based on race or gender they are positively associated with perceptions of social integration and open communication. However, when they are based on race and gender they are negatively associated with perceptions of social integration and open communication. The implications of this study demonstrate that subgroups may in many cases be beneficial rather than detrimental to virtual teams.
\end{abstract}

KEYWORDS: virtual teams; subgroups; diversity; social integration; computer-mediated communication.

\section{INTRODUCTION}

Virtual teams, teams with members who are geographically dispersed and rely primarily on some type of electronic communication, have become increasingly common $[1,46]$. Teams have become a favorite vehicle for addressing complex problems at many institutions in part because complex problems require multiple perspectives and a diverse knowledge base that one individual rarely possess [2, 18, 30, 31, 45, 49]. Now technology allows organizations to virtually assemble physically dispersed expertise in ways previously unavailable $[10,46]$. Despite the advantages of these virtual teams, they can present new challenges $[13,43]$. One such challenge centers around team composition. Virtual teams are often more diverse than their face-to-face counterparts, which can engender subgroup formation $[15,47]$.

Subgroup formation, the emergence of smaller groups within teams, has been found to have detrimental effects on teamwork in collocated $[17,24]$ and virtual teams [42]. For example, virtual teams with subgroups have been found to have higher conflict and coordination problems and lower trust [36, 42]. However, Gibson and Vermeulen [16] found an exception to the assertion that subgroups are inherently bad. They found that subgroup formation in collocated teams actually increased learning by providing social support and understanding for team members. Carton and Cummings [6] recently put forth a conceptual argument that could explain Gibson and Vermeulen's [16] findings. Carton and Cummings [6] proposed that the type of subgroups determines whether effects are negative or positive. Subgroups based on attributes other than race and gender could have positive impacts on teamwork. Despite their suggestion, the overwhelming amount of empirical evidence still suggests that subgroups are detrimental to teams (for a review see [55]).

The goal of this paper is to determine whether race and gender diversity can qualitatively change the impact of perceptions of subgroups in virtual teams. In accordance with Carton and Cummings [6], this paper proposes that when virtual teams are low in race and gender diversity, perceptions of subgroup formation are likely to be unrelated to identity characteristics and be positively associated with teamwork. However, when virtual teams are high in race and gender diversity, perceptions of subgroup formation are likely to be related to identity characteristics and be negatively associated with teamwork. 
To accomplish this goal, we conducted a multi-level investigation of the effects of individual perception of subgroup formation among 98 individuals in 25 virtual teams. The study examines the effects between racial and gender diversity and individual members' perceptions of subgroup formation on their feelings about social integration and open communications. An individual analysis was needed because the impact of subgroup formation varies across team membership. It is quite likely that one individual has different perceptions about the virtual team's climate from another within the same team.

This study extends prior literature on subgroups in virtual teams. More research is needed to better understand the effects of subgroup formation in virtual teams. Currently the research on subgroup formation in virtual teams has only proposed and found negative effects associated with subgroup formation in virtual teams [36, 42]. Results of this study could provide evidence that subgroup formation can actually be good for virtual teams. This study also extends the literature on subgroup formation in both collocated and virtual teams. By empirically testing Carton and Cummings' [6] assertion this paper provides empirical evidence for why subgroup formation can be both beneficial and detrimental to collocated and virtual teamwork.

\section{RELATED WORK}

Although many theories are used to explain the impacts of subgroup formation, most focus on explaining how individuals place themselves and others into in-groups and out-groups [55]. Members in the in-group are seen as like oneself while members of the out-group are viewed as different. The in-group members form the basis of their particular subgroup, which does not include out-group members. The effects of subgroups can vary. On one hand individuals may simply favor their subgroup members and prefer to interact with them more than others. On the other hand, individuals may hold negative attitudes about out-group members and avoid interacting with them [24, 27].

Subgroup formation has been associated with many negative outcomes. The positive bias toward team members within one's subgroup and the negative reactions toward those outside the subgroup can hamper inter-team relations [27]. Teams with subgroups can behave more like two uncooperative - or in some cases competing halves rather than one cohesive unit. As a result, subgroup formation decreases social integration variables like trust and satisfaction and increases relationship, task and process conflict [27, 54]. As result, subgroup formation can decrease knowledge-sharing [24] and team performance [22, 27, 55].

Researchers have recently begun to study the impacts of subgroup formation in virtual teams. Virtual teams with subgroup formation have been found to have significantly higher conflict and coordination problems, lower trust, lower team identification and lower-functioning transactive memory systems [36, 42]. At the individual level, team members have normally reported low levels of individual trust and higher levels of interpersonal conflict $[40,42]$. Similar effects were found in globally dispersed teams where subgroup formation was based on cultural and temporal distance [41].

\section{RESEARCH MODEL}

A central argument of this paper is that in virtual teams information about subgroup formation can be revealed through interactions. In addition, this paper proposes that perceptions can drive actions [19, 26, 57]. It is also expected that individual team members' perceptions vary within virtual teams. Therefore, this paper examines perceptions of subgroup formation in individual members of virtual teams. Figure 1 provides a summary of these arguments, which are elaborated below. 


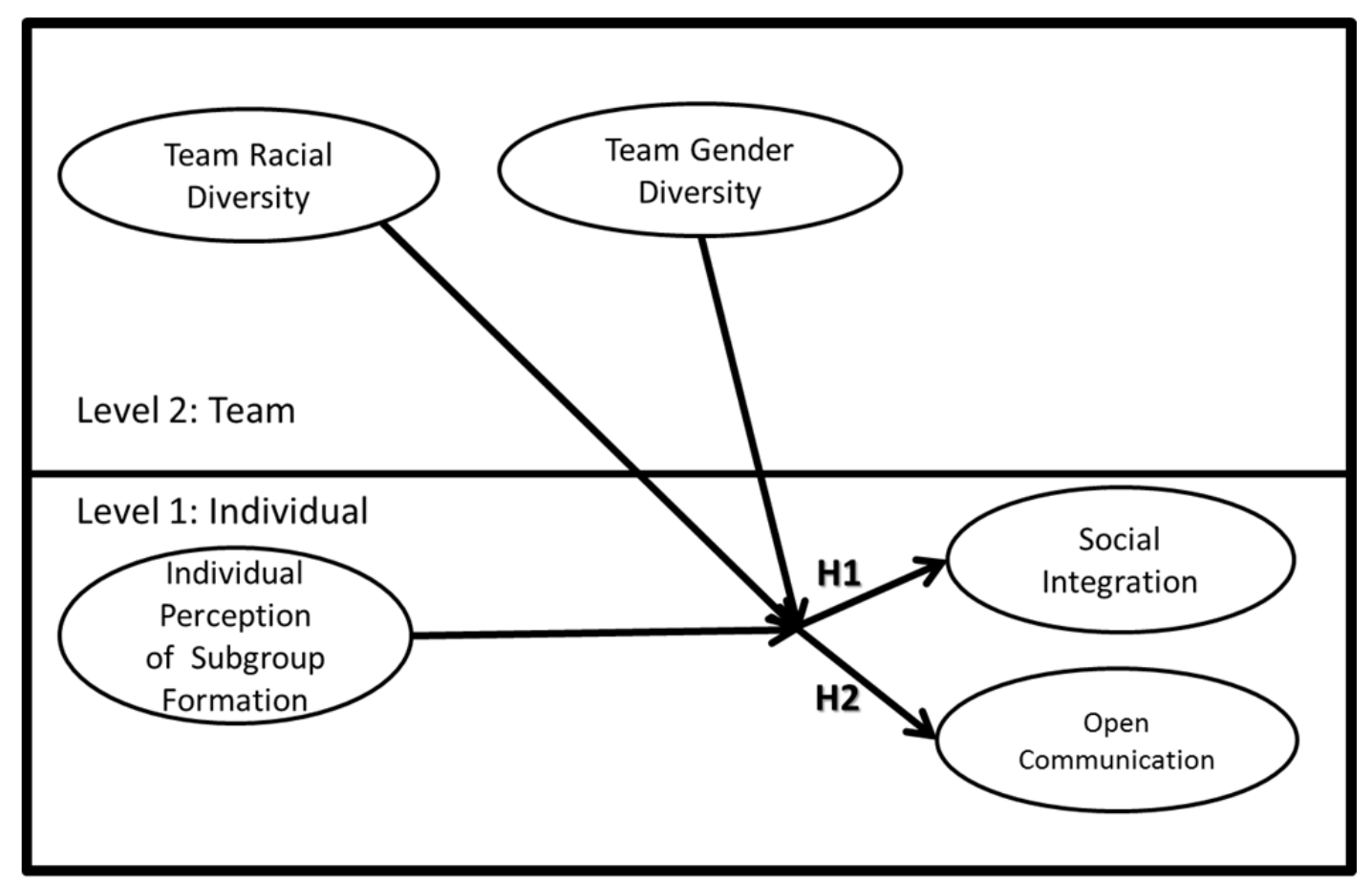

Figure 1: Research Model

\section{Subgroups, Racial and Gender Diversity and Social Integration}

Research shows that the nature of team interaction is an important driver of task performance, particularly in virtual teams [45]. Social integration is an emergent state that reflects the extent to which team members experience positive interactions with their teammates $[19,31,33]$. As a multidimensional construct, social integration is often measured through such elements as cohesion, satisfaction, trust and enjoyment $[19,38]$. Social integration has been a strong predictor of team performance in diverse collocated teams [19] and virtual teams [14, 31, 33].

Subgroups would be expected to have a strong positive effect on one's perceptions of social integration in virtual teams low in racial and gender diversity. Because subgroups consist of at least two individuals they can often ensure that everyone has at least one person to turn to for support [16]. This would be expected to act as a strong mechanism to promote perceptions of social integration among members of virtual teams. In addition, the lack of racial and gender diversity can reduce the tendency of individuals to react negatively to others not in their subgroups; race and gender similarity within teams can help create a common identity even when there are subgroups [22]. This common identity can increase the psychological closeness among team members and set the stage for team interactions $[19,29,46,53]$. For example, research has found that individuals in teams low in racial and gender diversity are more likely to recognize positive attributions of one another and be more forgiving of their teammates' mistakes $[23,39]$. Similarly to Gibson and Vermeulen [16], this paper proposes that the perceptions of subgroups in virtual teams low in racial and gender diversity are not likely to trigger negative reactions but instead be viewed as social support mechanisms. As such, perceptions of subgroup formation should be positively associated with social integration when racial and gender diversity is low.

Subgroups would be expected to have strong negative effects on social integration in virtual teams high in either racial or gender diversity. In these virtual teams subgroup formation is likely to be associated with either race or gender. This sets the stage for two potential problems. One, both racial and gender diversity in virtual teams have been found to decrease the ability of virtual teams to develop a common identity [47]. Two, this common identity has been found to be a key factor in overcoming the tendency of virtual team members to notice harsher dispositional attributes about, and lower cooperative behaviors toward, their teammates [20]. So, perceptions of 
subgroup formation in virtual teams high in racial and gender diversity are likely to be associated with a more a divisive team environment [5]. This makes for cold and potentially unpleasant interaction that can leave virtual team members feeling less satisfied and less engaged with the team [37, 44].

H1) Perceptions of subgroup formation are negatively related to perceptions of social integration in virtual teams high in racial or gender diversity but are positively related to perceptions of social integration when virtual teams are low in racial and gender diversity.

\section{Subgroups, Racial and Gender Diversity and Open Communications}

Teams are often viewed as information processors [9]. In this view teams act as processors of their members' multiple perspectives and information [28, 45, 52]. This requires an open communication environment where members share and exchange information. The ability of teams to exchange and share information is seen as the key to their ability to identify problems, generate alternatives and recommend solutions [28, 52]. An environment that promotes information exchange has been found to increase many types of team performance [45, 52]. The exchange and sharing of information has been found to be particularly important to the performance of dispersed teams [45].

The perceptions of subgroup formation can have a strong positive relationship with open communications in virtual teams low in racial and gender diversity. Individuals are often not forthcoming in team settings when they believe they hold a minority viewpoint [45]. Subgroups, which are composed of two or more members, can provide support to encourage team members to share their information. Subgroups can ensure that at least one other person will support that opinion [16]. Therefore, subgroups can encourage every member to share irrespective of the team's level of racial and gender diversity. However, the team's level of racial and gender diversity will impact how the information is received by other team members.

Members of virtual teams low in racial and gender diversity are more open to receive information from one another. Racial- and gender-homogenous teams tend to engage in more collaborative behaviors [19]. Collaborative behaviors are cooperative actions taken by the team and its members to provide supportive interactions [7]. This has been measured by acts of helpfulness and cooperativeness $[25,48]$. Therefore, the perceptions of subgroup formation in virtual teams low in racial and gender diversity are expected to be associated with a more open communication environment.

However, in virtual teams high in racial and gender diversity team members are not as receptive to information from one another. Research has found that racial or gender diversity can negatively affect the extent to which team members are willing to agree with and build on one another's ideas [8, 21, 22]. This is because racial and gender diversity can invoke in-group/out-group comparisons within teams [22]. And although the presence of subgroups can encourage information exchange, it may be met with hostile reactions $[8,21,22]$. Subgroup members in raceor gender-diverse teams are much more likely to defend another's similar ideas at the expense of promoting an open discussion [21]. This hinders the ability of team members to exchange and share information [22]. This assertion is indirectly supported by Polzer et al. [42]. They found that subgroups based on nationality in virtual teams led to members experiencing more conflict between subgroups [42]. Similarly to race and gender, subgroups based on nationality represent a type of identity-based subgroup [6]. Taken together, both theory and prior empirical evidence suggest that perceptions of subgroup formation in race- or gender-diverse virtual teams is negatively associated the perception of open team communications.

H2) Perceptions of subgroup formation are negatively related to perceptions of open team communications in virtual teams high in racial and/or gender diversity but are positively related to perceptions of open team communications when virtual teams are low in racial and gender diversity.

\section{METHOD}




\section{Participants}

The participants are students who were enrolled at a large public university's online global campus. This online campus is designed to provide distance education to working professionals. Students were assigned to teams as part of their course. All interactions among team members occurred online, so these teams were considered to be virtual teams. Typically, individuals were randomly assigned to teams; however, the final decision regarding team assignment was determined the instructor. The instructor was not aware of the research question or hypotheses being tested and none of the classes was taught by the author(s).

The participants' ages ranged from 26 to 49 with a mean of 37 . Thirty-one percent of the students were women and 66 percent were white Americans while 34 percent were black Americans. All the participants were U.S. citizens. A total of 98 students in 25 teams, representing 90 percent of students, participated in the study. Team size ranged from 3 to 5 members. Team projects lasted on average 47 days. The team project was a class requirement but the students received extra credit for completing the survey.

Teams were provided with access to Blackboard software as a communication technology. However, teams were allowed to use any outside communication software they chose. Teams were asked which types of communication technologies they employed. Fifty-four percent of team communications took place via email while 18 percent took place via chat, 19 percent via voice and 9 percent via video.

As part of their course requirement the teams were asked to complete an organizational system needs analysis. The project included an assessment of an organization's enterprise system. The teams were required to assess the system in relation to the information given to them about the organization. The teams then had to determine what capabilities the system had and what capabilities the organization needed. The team submitted one project to their instructor.

\section{Data Collection}

Data were collected via an online survey emailed to students. Surveys were emailed to participants on the day their assignment was due. Participants were asked to answer questions based on their team experiences and were informed that their responses would remain confidential. A seven-point Likert scale was used to measure all constructs.

Prior research on subgroup formation in virtual teams has found that subgroups can be based on the geographic location of members [36, 42]. In other words, if two of more members of a virtual team are physically located together, they could create a subgroup. To check for the possibility of geographic collocation among team members, virtual team members were asked to provide the location of their home and work. Based on this information, no team members were physically located at the same address or worked at the same location. In addition, team members were asked how much face-to-face interaction they had with their teammates. Team members indicated that they relied on some form of electronic communications to interact with teammates and did not have any face-to-face interactions.

\section{Control Variables}

We used several control variables to reduce the possibility of alternative explanations. These included team size and team tenure (life of the team).

\section{Independent Variables}

Gender and racial diversity were calculated via Blau's index [3]. Blau's index is defined as: $\mathrm{H}=1-\Sigma \mathrm{p} 2 \mathrm{i}$. Where $H$ is the heterogeneity score of a group, $p$ is the proportion of team members that falls into a particular category, and $i$ is the number of different categories represented in the team. 
Subgroup formation items were taken from Earley and Mosakowski [11]. Items included "Our group really consisted of several smaller groups of people based on how people interacted with each other."

\section{Dependent Variables}

There were two dependent variables, social integration and open team communications. Social integration was measured with items based on prior literature [44]. Items included "My team works well together as a team." Open team communications was measured with items from Earley and Mosakowski [11]. Items included "We really listen to one another and try to understand the feelings and points of view of each other."

\section{RESULTS}

Psychometric properties were analyzed for each construct. Convergent and discriminant validity were accessed by an exploratory factor analysis (Table 1). All items loaded at the level of 0.7 or above on each of their constructs; no cross-loadings were above 0.35 . Both are clear indications of convergent and discriminant validity [12]. The means, standard deviations and reliabilities are all listed in Table 2. The Cronbach alphas all ranged from 0.78 to 0.83 , indicating adequate reliability. Next, the intra-class correlation coefficients (ICC) were calculated for all latent constructs. All ICC values above 0.10 were used to provide evidence that there is a significant team effect [4].

Table 1: Factor Loading

\begin{tabular}{|c|c|c|c|}
\hline Item & 1 & 2 & 3 \\
\hline We really listen to one another and try to understand the feelings and points of view of each other. & 0.89 & & \\
\hline We had the freedom to express ourselves on any issue at any time. & 0.87 & & \\
\hline We freely express our feelings and ideas in meetings. & 0.78 & & \\
\hline After our planning session, it was clear that our group was divided into subgroups. & & 0.96 & \\
\hline $\begin{array}{l}\text { Our group really consisted of several smaller groups of people based on how people interacted with each } \\
\text { other. }\end{array}$ & & 0.98 & \\
\hline I trust all of the other team members. & & & 0.92 \\
\hline Overall this team project was a good experience. & & & 0.89 \\
\hline My team works well together as a team. & & & 0.82 \\
\hline
\end{tabular}

Table 2

Means, Standard Deviations, Reliabilities, and Correlations

\begin{tabular}{|l|c|c|c|c|c|c|c|c|c|}
\hline \multicolumn{1}{|c|}{ Variable } & Mean & $\begin{array}{c}\text { Std. } \\
\text { Dev. }\end{array}$ & Reliability & $\mathbf{1}$ & $\mathbf{2}$ & $\mathbf{3}$ & $\mathbf{4}$ & $\mathbf{5}$ & $\mathbf{6}$ \\
\hline $\begin{array}{l}\text { Individual Perception of Subgroup } \\
\text { Formation }\end{array}$ & 2.70 & 1.67 & 0.83 & & & & & & \\
\hline Gender Diversity & 0.30 & 0.18 & N/A & 0.02 & & & & & \\
\hline Racial Diversity & 0.21 & 0.21 & N/A & -0.07 & 0.14 & & & & \\
\hline Open Communications & 5.36 & 1.04 & 0.85 & -0.10 & -0.11 & -0.18 & & & \\
\hline Social Integration & 4.80 & 1.40 & 0.78 & 0.08 & -0.10 & -0.11 & $0.64^{\star \star}$ & & \\
\hline Team Size & 3.90 & 0.76 & N/A & -0.06 & 0.01 & $0.22^{\star}$ & -0.13 & -0.18 & \\
\hline Team Tenure & 47.00 & 22.00 & N/A & 0.21 & 0.19 & 0.07 & -0.10 & 0.14 & 0.16 \\
\hline
\end{tabular}

Notes: 1. Significance of correlations: ${ }^{*} p<0.01 ;{ }^{*} p<0.05$ 


\section{2. $N=98$}

Hypotheses 1 and 2 posited the interaction effects between both team- and individual-level variables. This required the use of multi-level analysis [4]. We used SPSS 21.0 (IBM, Armonk, NY) mixed-model package to perform hierarchical linear modeling (HLM) to test the proposed model. The results of the multi-level analysis are shown in Table 3. Model 1 shows the effects of control variables on the dependent variables. Model 2 shows the direct effects of the main effects. Model 3 shows the two-way interaction effects and Model 4 shows the full model with the three-way interaction effect.

Table 3. Results of Multi-Level Analysis

\begin{tabular}{|c|c|c|c|c|c|c|c|c|}
\hline \multirow[t]{2}{*}{ Independent Variables } & \multicolumn{4}{|c|}{ Social Integration } & \multicolumn{4}{|c|}{ Open Communications } \\
\hline & 1 & 2 & 3 & 4 & 1 & 2 & 3 & 4 \\
\hline \multicolumn{9}{|l|}{ Control Variables } \\
\hline Team Size & -0.13 & -0.18 & -0.17 & 0 & -0.1 & -0.1 & -0.01 & 0.12 \\
\hline Team Tenure & 0.19 & 0.33 & 0.33 & 0.16 & -0.04 & 0.08 & 0.04 & 0.07 \\
\hline \multicolumn{9}{|l|}{ Main Effects (Level 1) } \\
\hline $\begin{array}{l}\text { Individual Perception } \\
\text { of Subgroup Formation }\end{array}$ & & $-0.62^{*}$ & $-0.69 *$ & $-0.62^{*}$ & & $-0.53^{*}$ & $-0.49^{*}$ & $-0.44^{*}$ \\
\hline \multicolumn{9}{|l|}{ Main Effects (Level 2) } \\
\hline Racial Diversity & & 0.09 & 0.07 & 0.1 & & -0.08 & -0.01 & 0.02 \\
\hline Gender Diversity & & -0.22 & -0.19 & -0.1 & & -0.09 & -0.08 & -0.01 \\
\hline \multicolumn{9}{|c|}{ 2-Way Cross-Level Interactions } \\
\hline $\begin{array}{l}\text { Individual Perception } \\
\text { of Subgroup Formation X } \\
\text { Racial Diversity }\end{array}$ & & & -0.11 & -0.39 & & & -0.11 & -0.3 \\
\hline $\begin{array}{l}\text { Individual Perception } \\
\text { of Subgroup Formation X } \\
\text { Gender Diversity }\end{array}$ & & & -0.21 & -0.33 & & & -0.34 & -0.42 \\
\hline Racial X Gender Diversity & & & 0.12 & -0.04 & & & -0.13 & -0.24 \\
\hline \multicolumn{9}{|c|}{ 3-Way Cross-Level Interactions } \\
\hline $\begin{array}{l}\text { Individual Perception } \\
\text { of Subgroup Formation X } \\
\text { Racial Diversity X } \\
\text { Gender Diversity }\end{array}$ & & & & $0.63^{*}$ & & & & $0.42^{\star}$ \\
\hline -2 Restricted Log Likelihood & 266 & 264 & 265 & 215 & 219 & 218 & 220 & 217 \\
\hline Deviance Difference & & 2 & -1 & 50 & & 2 & -1 & 50 \\
\hline Df & & 2 & 3 & 3 & & 2 & 3 & 3 \\
\hline $\mathrm{R}^{2}$ & 0 & $5.0 \%$ & $16.0 \%$ & $33.0 \%$ & 0 & $6.3 \%$ & $6.3 \%$ & $12.0 \%$ \\
\hline Change $\mathrm{R}^{2}$ & & & $11.0 \%$ & $17.0 \%$ & & & $0.0 \%$ & $5.7 \%$ \\
\hline
\end{tabular}

${ }^{*} p<0.05,{ }^{* \star} p<0.01,{ }^{* \star *} p<0.001$

Both hypotheses were supported and plotted in Figures 2 and 3. Perceptions of subgroup formation was significantly negatively related to both social integration and open team communications when either racial or gender diversity was high, and perceptions were significantly positively related to both social integration and open team communications when both racial and gender diversity were low. 


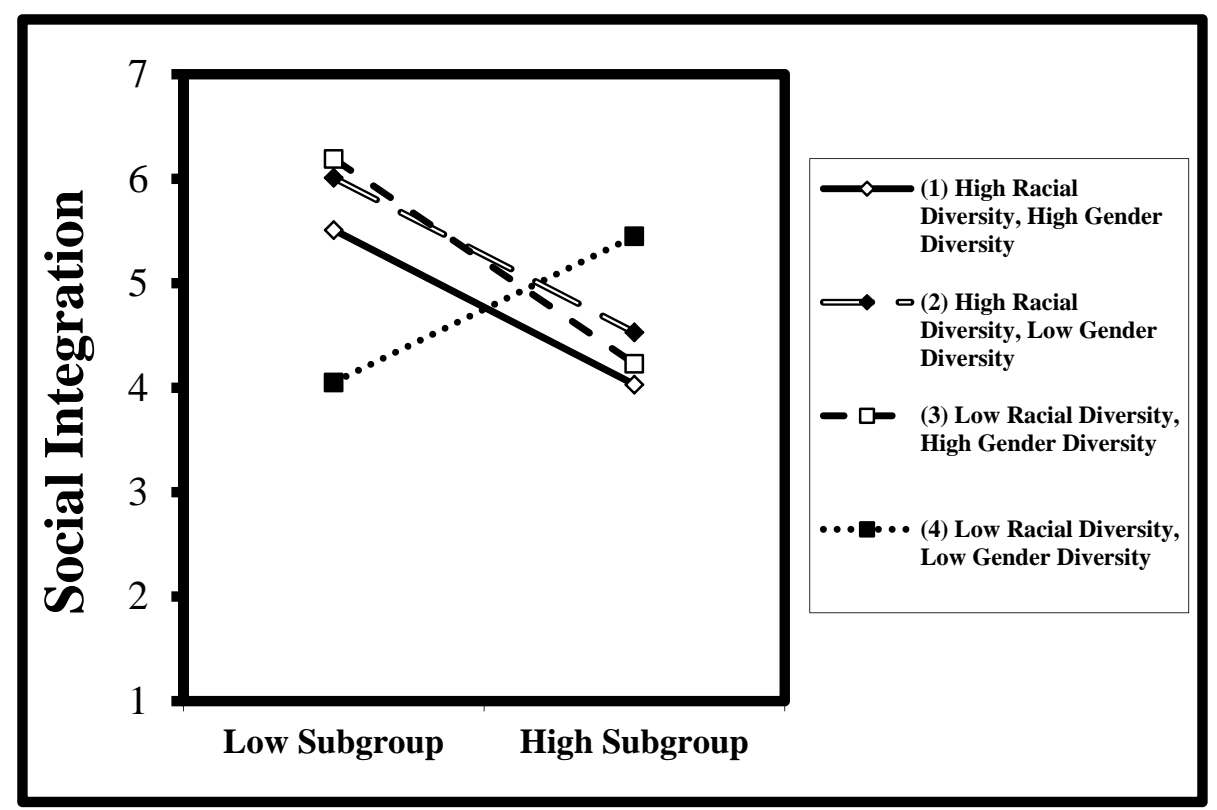

Figure 1

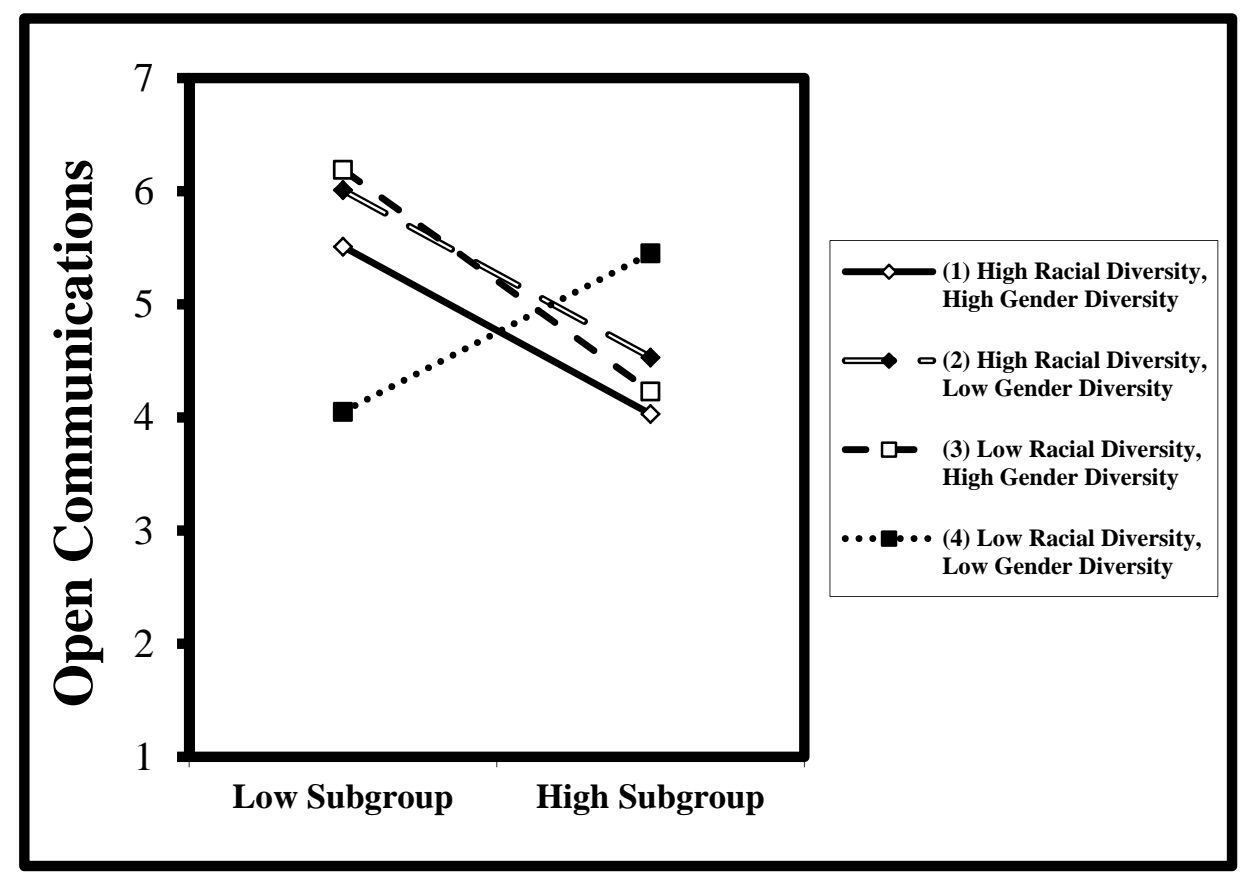

Figure 2

\section{DISCUSSION}

The objective of this study was to determine whether the relationships between subgroup formation and social integration and open communications in virtual teams were moderated by racial and gender diversity in virtual teams. Results indicate that the racial and gender composition of virtual teams determined the impact of the perceptions of subgroups. The perceptions of subgroup formation were associated with increases social integration 
and open communications when racial and gender diversity in virtual teams were low; however the opposite was true when the racial and gender diversity in virtual teams were high.

Results of this study contribute to our understanding of diversity in virtual teams. Prior research on diversity in virtual teams has found that actual diversity like race, gender and age often does not have main effects [15, 51]. But instead the effects of team diversity seem to be contingent on contextual factors. These results parallel the research on team diversity in collocated teams $[22,56]$. In both multilevel analyses racial and gender diversity did not have any main effects. They only became significant when coupled with perceptions of subgroup formation. Therefore, the results of this study provide further evidence of the contingent effects of team diversity in virtual teams while identifying a new moderator of their effects.

This study also contributes to our knowledge on subgroup formation. Results indicate that race and gender qualitatively change the impacts of the perceptions of subgroups. In the absence of race and gender diversity, subgroups are associated with positive benefits in virtual teams. This seems to provide some support for Carton and Cummings' [6] assertion that different types of subgroups can have qualitatively different impacts on teamwork. These findings support the minority view that subgroups can have positive team effects. At the same time, these findings help to explain why subgroups can have a negative effect. In doing so, this study helps to reconcile some of the mixed findings presented in the subgroup literature.

\section{Implications for Theory}

This study has several implications for theory. One, virtual team members in this study had full access to each member's identity as classmates. There was no attempt to hide the racial or gender identity of any team member. For example, all communications between team members included the sender's name. However, future studies would be useful to determine whether race and gender can be suppressed, and if so, whether this would reduce their negative effects when coupled with perceptions of subgroup formation.

Two, prior research on team diversity in both collocated and virtual teams has emphasize either actual or perceived diversity [19]. Although actual diversity is represented by actual differences, perceived diversity is represented by the perceptions of differences among team members [31,33]. Our study found an interaction between both actual diversity and perceptions. This may indicate that both actual and perceptual measures are needed to fully account for the effects of team diversity.

\section{Limitations}

This study has several limitations. First, this study employed a cross-sectional research design. As in any study employing a cross-sectional research design, it is difficult to draw causal inferences. However, by using objective measures of team diversity this study potentially reduced the impact of common method bias normally associated with cross-sectional research designs. Second, this study used self-reported measures of race and gender. However, there can be other conceptualizations and measures of gender and race. The use of other conceptualizations and measures may provide different results. Finally, the participants of this study were graduate students enrolled in a distance-education course. Although students typically differ from full-time employees in terms of age and experience, these participants were of similar age (average 37) to employees working in many organizations. Nonetheless, these individuals were not embedded within an organization, and as such they were not exposed to organizational cultural or policy influences. Future studies may attempt to replicate these findings in an organizational context.

\section{Practical Implications}

The paper has several practical implications. Research has found that training and leadership styles can mitigate some of the negative effects associated with subgroup formation [34, 35]. Managers may want to take an active lead in heading off potential problems associated with racial and gender diversity resulting from subgroup formation. Creation of a common identity among people of diverse racial backgrounds and genders can be difficult but is 
clearly not impossible [22]. Managers may need to leverage their company's organizational identity to help create this common identity in diverse virtual teams.

\section{Conclusion}

We sought to extend our understanding of the effects of subgroup formation in race- and gender-diverse virtual teams. We found that the impact of subgroup formation can be dependent on a virtual team's racial and gender diversity. Perceptions of subgroup formation were negatively related to social integration and open communications when racial and gender diversity were high but not when they were low. By taking a multi-level approach we were able to see how the impact of race and gender varied individually among members of virtual teams.

\section{REFERENCES}

[1] Alnuaimi, O. Maruping, L.M., Robert, L.P. "Social loafing in brainstorming CMC teams: the role of moral disengagement," proceedings of the 42nd International Conference on System Sciences, Big Island, HI: Jan. 5-8, 2009, 1-9.

[2] Alnuaimi, O.A., Robert, L.P., and Maruping, L.M. "Team size, dispersion, and social loafing in technologysupported teams: A perspective on the theory of moral disengagement," Journal of Management Information Systems 27:(1), 2010, 203-230.

[3] Blau, P.M. Inequality and heterogeneity: A primitive theory of social structure, Free Press, New York, NY, 1977.

[4] Bliese, P.D. "Within-group agreement, non-independence, and reliability: Implications for data aggregation and analysis." In K.J. Klein and S.W.J. Kozlowski (Eds.), Multilevel theory, research, and methods in organizations: Foundations, extensions, and new directions, Jossey-Bass, San Francisco, CA, 2000, 349381.

[5] Bos, N.D., Buyuktur, A., Olson, J.S., Olson G.M., Voida, A. "Shared identity helps partially distributed teams, but distance still matters." Group 2010 proceedings of the $16^{\text {th }}$ ACM International Conference on Supporting Group Work, New York, NY: 2010, 89-96.

[6] Carton, A.M., Cummings, J.N. "A theory of subgroups in work teams," Academy of Management Review 37, 2012, 441-470.

[7] Chatman, J.A. "Norms in mixed sex and mixed race work groups," Academy of Management Annals 4(1), 2010, 447-484.

[8] Dahlin, K., Weingart, L.R., Hinds, P. "Team diversity and information use," Academy of Management Journal 46, 2005, 1107-1123.

[9] De Dreu, C.K.W., West, M.A. "Minority dissent and team innovation: The importance of participation in decision making," Journal of Applied Pyschology, 86, 2001, 1191-1201.

[10] Dennis, A.R., Robert, L.P., Curtis, A.M., Kowalczyk, S.T., Hasty, B.K. "Trust is in the eye of the beholder: A vignette study of postevent behavioral controls' effects on individual trust in virtual teams," Information Systems Research 23:(2), 2012, 546-558.

[11] Earley, P.C., Mosakowski, E. "Creating hybrid team cultures: An empirical test of transnational team functioning," Academy of Management Journal 43, 2000, 26-49.

[12] Fornell, C., Larcker, D.F. "Evaluating structural equations models with unobservable variables and measurement error," Journal of Marketing Research, 18:(1), 1981, 39-50.

[13] Furumo, K. "The Impact of conflict and conflict management style on deadbeats and deserters in virtual teams," Journal of Computer Information Systems 49:(4), 2009, 66-73.

[14] Garrison, G., Wakefield, R.L., Xu, X., Kim, S.H. "Globally distributed teams: the effect of diversity on trust, cohesion and individual performance," DATABASE Advances in Information Systems 41:(3), 2010, 27-48.

[15] Giambatista, R.C., Bhappu, A.D. "Diversity's Harvest: Interactions of diversity sources and communication technology on creative group performance," Organizational Behavior and Human Decision Processes 
111:(2), 2010, 116-126.

[16] Gibson, C., Vermeulen, F. "A healthy divide: Subgroups as a stimulus for team learning behavior," Administrative Science Quarterly 48, 2003, 202-239.

[17] Goyal, S.L. Maruping, L., Robert, L.P. "Diversity and conflict in teams: A faultline model perspective," proceedings of the Academy of Management Conference, Anaheim, CA, Aug. 1, 2008, pp. 1-6.

[18] Han, J.Y., Hovav, A. "Dimensionality of social capital and organizational citizenship behavior in information systems project teams," Journal of Computer Information Systems [In press].

[19] Harrison, D.A., Price, K.H., Gavin, J.H., Florey, A.T. "Time, teams, and task performance: Changing effects of surface- and deep-level diversity on group functioning." Academy of Management Journal 45:(5), 2002, 1029-1045.

[20] Hinds, P.J., Mortensen, M. "Understanding conflict in geographically distributed teams: The moderating effects of shared identity, shared context, and spontaneous communication," Organization Science 16:(3), 2005, 290-307.

[21] Homan, A.C., van Knippenberg, D., van Kleef, G.A., De Dreu, C.K.W. "Bridging faultlines by valuing diversity: The effects of diversity beliefs on information elaboration and performance in diverse work groups," Journal of Applied Psychology 92, 2007, 1189-1199.

[22] Homan, A.C., Hollenbeck, J.R., Humphrey, S.E., van Knippenberg, D., Ilgen, D.R., Van Kleef, G.A. "Facing differences with an open mind: Openness to experience, salience of intra-group differences, and performance of diverse work groups," Academy of Management Journal 51:(6), 2008, 1204-1222.

[23] Hutchings, K., Michailova, S. "Facilitating knowledge sharing in Russian and Chinese subsidiaries: The role of personal networks and group membership," Journal of Knowledge Management, 8, 2004, 84-94.

[24] Lau, D., Murnighan, J. "Interactions within groups and subgroups: The effects of demographic faultlines," Academy of Management Journal 48, 2005, 645-659.

[25] LePine, J.A., Van Dyne, L. "Voice and cooperative behavior as contrasting forms of contextual performance: Evidence of differential relationships with big five personality characteristics and cognitive ability," Journal of Applied Psychology 86, 2001, 326-336.

[26] Liao, H., Chuang, A., Joshi, A. "Perceived deep-level dissimilarity: Personality antecedents and impact on overall job attitude, helping, work withdrawal, and turnover," Organizational Behavior and Human Decision Processes 106:(2), 2008, 106-124.

[27] Li, J., Hambrick, D. "Factional groups: A new vantage on demographic faultlines, conflict, and disintegration in work teams," Academy of Management Journal 48, 2005, 794-813.

[28] Lin T.-C., Hsu J.S.-C., Cheng K.-T. and Wu S. "Understanding the role of behavioural integration in ISD teams: an extension of transactive memory systems concept," Information Systems Journal 22:(3), 2012, 211-234.

[29] Mortensen, M., Hinds, P.J. "Conflict and shared identity in geographically distributed teams," International Journal of Conflict Management 12:(3), 2001, 212-238.

[30] Munson, S.A., Kervin, K., Robert, Jr., L.P. "Monitoring email to indicate project team performance and mutual attraction," Proceedings of the 17th ACM conference on computer-supported cooperative work \& social computing, Baltimore, Maryland: 2014, 542-549.

[31] Nesterkin, D.A., Porterfield, T.E., Li, X. "Relationship conflict, conflict management and performance of information technology teams," Journal of Computer Information Systems [In press].

[32] Newell, J., Maruping, L.M., Riemenschneider, C., Robert, L.P. "Leveraging E-identities: The impact of perceived diversity on team social integration and performance," proceedings of ICIS 2008, paper 46. Retrieved at http://aisel.aisnet.org/icis2008/46

[33] Newell, J., Robert, L.P., Riemenschneider, C., Maruping, L.M. "Influencing individual perceptions of deep level diversity in virtual learning teams (VLT)," proceedings of the $42^{\text {nd }}$ International Conference on System Sciences, Big Island, HI: Jan. 5-8, 2009, 1-10. 
[34] Ocker, R.J., Kracaw, D., Hiltz, S.R., Rosson, M.B., Plotnick, L. "Enhancing learning experiences in partially distributed teams: Training students to work effectively across distances," proceedings of the 42th Hawaii International Conference on System Sciences, Big Island, HI: Jan. 5-8, 2009.

[35] Ocker, R.J., Huang, H., Benbunan-Fich, R., and Hiltz, S.R. "Leadership dynamics in partially distributed teams: An exploratory study of the effects of configuration and Distance," Group Decision and Negotiation (20), 2011, 273-292.

[36] O'Leary, M., Mortenson, M. "Go (Con)figure: Subgroups, Imbalance, and Isolates in Geographically Dispersed Teams," Organizational Science 21:(1), 2010, 115-31.

[37] Olson, G.M., Olson, J.S. "Distance matters," Human-Computer Interaction 15:(2), 2000, 139-179.

[38] O'Reilly, C.A., Caldwell, D.F., Barnett, W.P. "Work group demography, social integration, and turnover," Administrative Science Quarterly 34, 1989, 21-37.

[39] Parker, S.K., Axtell, C.M. "Seeing another viewpoint: Antecedents and outcomes of employee perspective taking," Academy of Management Journal 44, 2001, 1085-1100.

[40] Plotnick, L., Ocker, R., Hiltz, S., Rosson, M.B. "Leadership roles and communication issues in partially distributed emergency response software development teams: A pilot study," proceedings of the 41st Hawaii International Conference on System Sciences, Big Island, HI: Jan. 7-10, 2008.

[41] Plotnick, L., Hiltz, S.R., Ocker, R. "Trust over time and distance in global partially distributed teams," proceedings of the 44th Hawaii International Conference on System Sciences, Kauai, HI: Jan. 4-7, 2011, 110.

[42] Polzer, J.T., Crisp, B., Jarvenpaa, S.L., Kim, J.W. "Extending the Faultline Concept to Geographically Dispersed Teams: How collocated subgroups can impair group functioning," Academy of Management Journal 49:(4), 2006, 679-692.

[43] Reed, A.H., Knight, L.V. "Project risk differences between virtual and co-located teams," Journal of Computer Information Systems 51:(1), 2010, 19-30.

[44] Rico, R. "The effects of diversity faultlines and team task autonomy on decision quality and social integration," Journal of Management 33:(1), 2007, 111-132.

[45] Robert, L.P., Dennis, A.R., Ahuja, M.K. "Social capital and knowledge integration in digitally enabled teams," Information Systems Research 19:(3), 2008, 1-21.

[46] Robert, L.P., Dennis, A.R., Hung, Y.-T.C. "Individual swift trust and knowledge-based trust in face-to-face and virtual team members," Journal of Management Information Systems 26:(2), 2009, 241-279.

[47] Robert, L.P. "A multi-level analysis of the impact of shared leadership in diverse virtual teams," proceedings of Computer Supported Cooperative Work conference San Antonio, Texas: 2013, 363-374.

[48] Simsek, Z., Veiga, J.F., Lubatkin, M.H., Dino, R.N. "Modeling the multilevel determinants of top management team behavioral integration," Academy of Management Journal 48, 2005, 69-84.

[49] Srinivasan, S.-S., Maruping, L.M., Robert, L.P. "Idea generation in technology-supported teams: A multilevel motivational perspective system science," proceedings of the Hawaii International Conference on System Science, Maui, HI: Jan. 4-7, 2012, 247-256.

[50] Srinivasan, S.-S., Maruping, L.M., Robert, L.P. "Mechanisms underlying social loafing in technology teams: An empirical analysis," Proceedings of ICIS 2010, St. Louis, Missouri: 2010, paper 183. Retrieved at http://aisel.aisnet.org/icis2010_submissions/183

[51] Staples, D.S., Zhao, L. "The effects of cultural diversity in virtual teams versus face-to-face teams," Group Decision and Negotiation 15:(4), 2006, 389-406.

[52] Tiwana, A., Mclean, E. "Expertise integration and creativity in information systems development," Journal of Management Information Systems 22:(1), 2005, 13-43.

[53] Turner, J.C. Social categorization and the self-concept: A social cognitive theory of group behavior, vol. 2, JAI Press, Greenwich, CT, 1985. 
[54] Thatcher, S.M.B., Patel, P.C. "Demographic faultlines: A meta-analysis of the literature," Journal of Applied Psychology, 96, 2011, 1119-1139.

[55] Thatcher, S.M.B., Patel, P.C. "Group faultlines: A review, integration, and guide to future research," Journal of Management 38:(2), 2012, 969-1009.

[56] Van Knippenberg, D., Schippers, M.C. "Work group diversity," Annual Review of Psychology 58:(1), 2007, 515-541.

[57] Zellmer-Bruhn, M.E., Maloney, M.M., Bhappu, A.D., Salvador, R. "When and how do differences matter? An exploration of perceived similarity in teams," Organizational Behavior and Human Decision Processes $107:(1), 2008,41-59$. 